\title{
Pediatric liver transplantation in Korea: long-term outcomes and allocations
}

\author{
Sanghoon Lee, Suk-Koo Lee \\ Department of Surgery, Samsung Medical Center, Sungkyunkwan University School of Medicine, Seoul, Korea
}

Pediatric liver transplantation has evolved into an effective treatment for a variety of liver diseases in the pediatric population. Over the past 25 years, pediatric liver transplantation results in Korea have matched international standards, and Korea has become one of the most important leaders in living donor liver transplantation. This review presents the cumulative outcomes of pediatric liver transplants in Korea and highlights other concerns related to pediatric liver transplantation, particularly pediatric liver allocation policy and split liver transplantation.

Keywords: Pediatric; Liver transplantation; Allocation

\section{INTRODUCTION}

The first liver transplantation (LT) was performed for a baby with biliary atresia in 1963 by Starzl [1]. LT in children has undergone significant progress and spreads worldwide owing to the development of potent immunosuppressants, better surgical techniques, and systematic perioperative, and long-term recipient management protocols. More than 50 years have passed since the first successful case, and LT is indicated in the definitive treatment of a multitude of diseases presenting during childhood [2]. The survival rate of infants with biliary atresia has increased dramatically and various inborn errors of metabolism have now become curable [3,4].

In this review, we will summarize the current status of pediatric LT in Korea and discuss allocation policies involving pediatric braindead donors and liver recipients,

Received February 10, 2019

Accepted March 27, 2019

Correspondence to: Suk-Koo Lee

Department of Surgery, Samsung Medical Center, Sungkyunkwan University School of Medicine, 81 Irwon-ro, Gangnam-gu, Seoul 06351, Korea

Tel: +82-2-3410-3477, Fax: +82-2-3410-0040

E-mail: sukkoo.lee@samsung.com which has become a recent topic of interest in pediatric LT in Korea.

\section{STATUS OF PEDIATRIC LT IN KOREA}

Pediatric LT Indications and Posttransplant Survival The first reported case of pediatric LT in Korea was in 1988; the recipient was a 14-year-old girl with Wilson disease [5]. The first successful pediatric LT from a living donor was performed in 1994. Since then, more than 1,000 pediatric LT procedures have been performed in Korea, and approximately 60 are performed annually (Fig. 1).

Indications for pediatric LT are classified into five categories [6]. The first indication includes primary liver diseases resulting in liver failure, such as viral hepatitis, acute liver failure, and the most common indication for pediatric LT, biliary atresia. The second indication includes diseases that do not lead to liver failure but involve critical complications: Alagille syndrome is one such disorder, and LT may be considered when severe pruritus, growth failure, malnutrition, and hyperlipidemia profoundly interfere with daily life. Inborn errors of metabolism are the third category of pediatric LT indications and include Wilson disease, glycogen storage disease, and urea cycle defects. The 

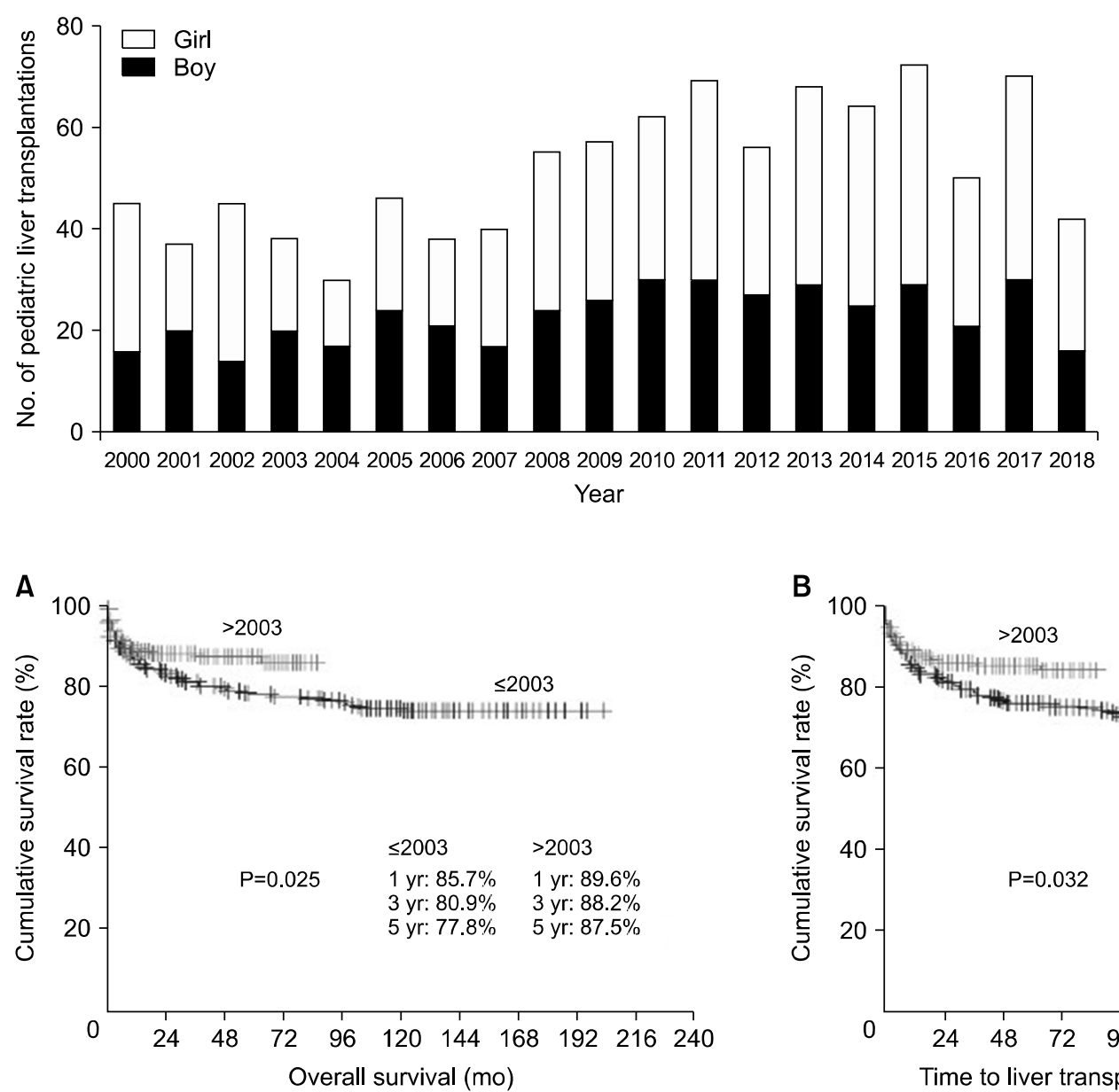

Fig. 1. Annual number of pediatric liver transplantations performed in Korea (2000-2018).

Fig. 2. Survival rate of patients (A) and grafts (B) in pediatric liver transplantation.

fourth indication is secondary liver disease from the hepatic manifestation of a systemic disorder such as cystic fibrosis. Cystic fibrosis may manifest as liver cirrhosis, but no cases have been reported in Korea to date. Liver malignancies that are managed with LT in childhood include hepatoblastoma and, less commonly, hepatocellular carcinoma [7]. In a study by Kim et al. [8] involving 534 cases of pediatric LT from four high-volume centers in Korea, biliary atresia was by far the most common indication for pediatric LT, with 308 reported cases.

Patient survival rates after pediatric LT in Korea are reportedly $87.8 \%, 84.5 \%, 78.1 \%$, and $52.2 \%$ at $1,3,5$, and 10 years, while graft survival rates are $86.9 \%, 82.1 \%$, $80.1 \%$, and $75.9 \%$, respectively [8]. These survival outcomes are comparable to results reported by leading centers in North America and have improved since 2003. These improvements show that better surgical and peri-

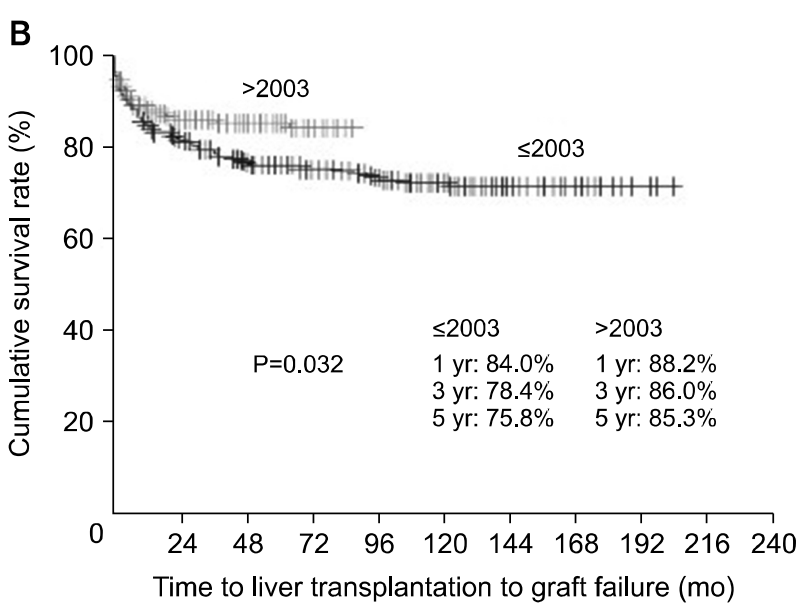

transplant patient management techniques have led to tangible advances in patient outcomes (Fig. 2).

A study by Lee et al. [9] analyzed 44 pediatric LT recipients with a follow-up exceeding 10 years. At a median 150 months after LT, 43 children had functioning grafts and one patient underwent a second LT. After initial discharge during the postoperative period, there were 248 instances of readmissions ( 0.56 readmission/person-years) (Fig. 3). Weight and height reached the 50th percentile at 3 and 5 years posttransplant, respectively. Forty-four recipients were either attending school at their age-appropriate grades or had completed their education. No patients had to repeat a school year.

\section{Pediatric Liver Allocation Policies}

Liver grafts utilized in pediatric LT may originate from living or deceased donors. A child receiving a liver graft from 

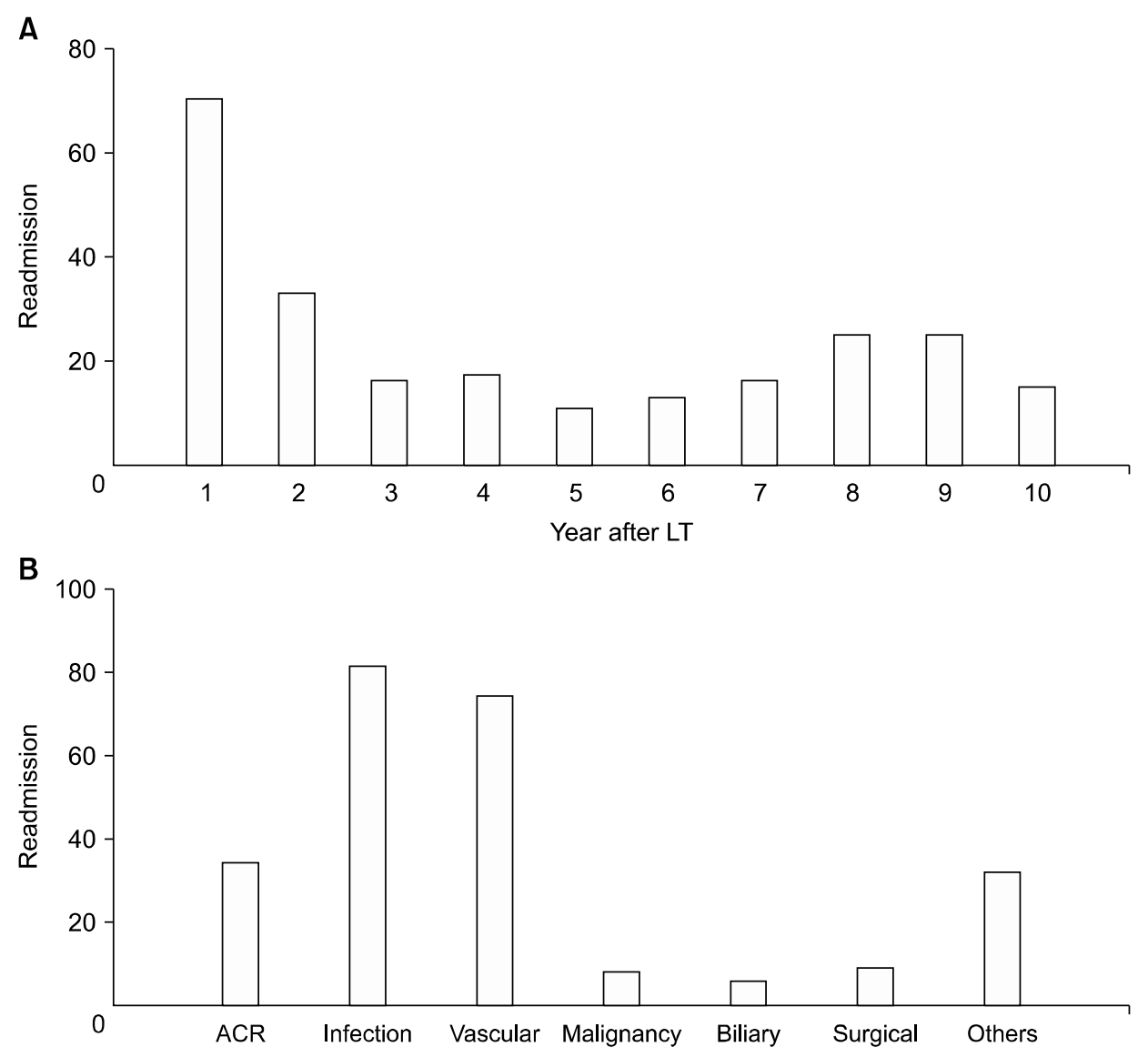

Fig. 3. Hospital readmissions by years after liver transplantation (LT; A) and causes of hospital readmissions (B) in 10-year survivors of pediatric LT. ACR, acute cellular rejection.

Table 1. Selection criteria for split liver transplantation

\begin{tabular}{ll}
\hline \multicolumn{1}{c}{ Before revision } & Revision in March 2013 \\
\hline Age below 16 years & Age below 16 years \\
Body weight below $30 \mathrm{~kg}$ & Body weight below 30 kg \\
Procurement less than left & $\begin{array}{l}\text { Procurement less than left } \\
\text { lateral section }\end{array}$ \\
His/her parents must be & \\
unsuitable for liver donors \\
(i.e., ABO incompatibility, \\
HBsAg(+), anti-HCV(+), etc.). \\
\hline
\end{tabular}

HBsAg, hepatitis B surface antigen; HCV, hepatitis C virus.

a deceased donor may receive a whole or split liver graft depending on their body weight. In the past, more than $80 \%$ of pediatric LT procedures involved living donor transplants. This deviation toward living donor grafts resulted from the absolute shortage of whole liver grafts available for pediatric recipients, who were not given priority for pediatric deceased donors; there were strict re- strictions for pediatric split LT and potential deceased donor split livers were not being fully utilized [10].

One recent change in the pediatric liver graft allocation policy was the alleviation of strict restrictions for pediatric split LT. Split LT is the technique of procuring two liver allografts (left liver graft and right liver graft) from a single deceased donor and transplanting them into two recipients (usually one adult and one child). With the current shortage of pediatric deceased donors in Korea, split LT provides the pediatric liver waitlist candidate with a greater chance for the successful allocation of a deceased donor liver graft. In the past, many pediatric LT candidates were not eligible for split LT because of a clause stating restriction for candidates with potential living parental donors (Table 1). However, this restriction clause was revised in 2013, increasing the number of eligible pediatric candidates for split LT.

An important issue that remains unresolved regarding pediatric liver allocation is the lack of regulations priori- 


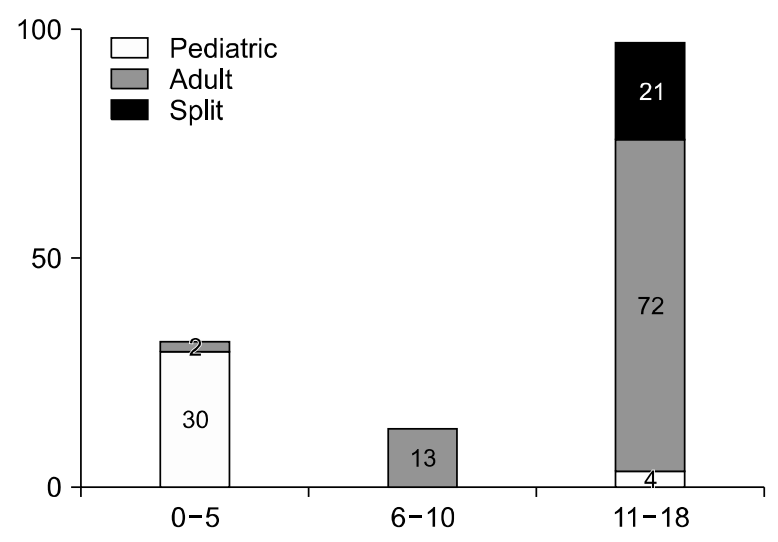

Fig. 4. Recipients of pediatric braindead donor livers in Korea (2011-2016). A large majority of livers from braindead donors age 6 years and older were allocated to adult recipients.

tizing pediatric candidates for grafts from pediatric deceased donors. Choi et al. [11] analyzed Korean Network for Organ Sharing (KONOS) data from 2006 to 2012 and showed that of 1,371 deceased donors, 85 (6.2\%) were younger than 18 years of age. However, 58 liver grafts from these 85 pediatric donors were allocated to adult recipients, while $82.1 \%$ of livers from pediatric donors older than 11 years were transplanted to adults. Data from 2011 to 2016 show the same results: all livers from donors aged 6 to 10 years were transplanted to adults and all but one liver graft from donors aged 11 to 18 years were transplanted to adult recipients (not considering 21 split cases) (Fig. 4) [12]. In contrast, the Organ Procurement and Transplantation Network (OPTN) of North America clearly prioritized pediatric potential transplant recipients when allocating livers from pediatric deceased donors [13]. The ethical principles behind their pediatric organ allocation policy is elucidated by the OPTN/United Network for Organ Sharing Pediatric Transplantation and Ethics Committees [14], which states that the National Organ Transplant Act charges the OPTN to recognize the differences in health and organ transplantation issues between children and adults throughout the system and adopt criteria, policies, and procedures that address the unique health care needs of children. It also states that the Committees are aware that many stakeholders in transplantation feel particularly sympathetic to the needs of children and providing resources to protect them and help them thrive is a fundamental human instinct. These con- cepts have not yet been popularized or incorporated into organ allocation policies in Korea. However, talks have begun among experts in the field regarding the potential disadvantages that pediatric candidates experience, and such issues have recently been topics of discussion in academic meetings of the Korean Society for Transplantation and the Korean Liver Transplantation Society.

Another related issue is the conformity with which KONOS pediatric liver allocation criteria are set up. Besides status one conditions (fulminant liver failure, primary nonfunction or hepatic artery thrombosis following LT, or acute liver failure with underlying Wilson disease), having a high pediatric end-stage liver disease score is the only way to ensure a high probability of liver allocation in pediatric candidates [15]. However, many grave conditions that require LT in children do not harbor abnormal liver function. Inborn errors of metabolism, such as urea cycle disorders or organic acidemia and hepatoblastoma, are representative examples of such conditions. The distinctiveness of these pediatric diseases should be considered in future discussions to bring about change in pediatric liver allocation policies.

\section{CONCLUSIONS}

Pediatric LT has evolved significantly since its introduction 30 years ago. It has reached a plateau in terms of case volume, but the diversity in indications has widened and survival outcomes are comparable to global standards. Future issues in pediatric LT in Korea involve updating recipient criteria for the allocation of braindead donor livers, especially those from pediatric donors, to facilitate the special needs of children on the pediatric LT waitlist.

\section{CONFLICT OF INTEREST}

No potential conflict of interest relevant to this article was reported.

\section{ORCID}

Sanghoon Lee https://orcid.org/0000-0002-5086-1461

Suk-Koo Lee https://orcid.org/0000-0002-8503-2882 


\section{REFERENCES}

1. Starzl TE, Koep LJ, Schröter GP, Halgrimson CG, Porter KA, Weil R 3rd. Liver replacement for pediatric patients. Pediatrics 1979;63:825-9.

2. Kim MJ, Choe YH. Indication of pediatric liver transplantation. J Korean Soc Transplant 2011;25:151-4.

3. Ryckman FC, Alonso MH, Bucuvalas JC, Balistreri WF. Biliary atresia: surgical management and treatment options as they relate to outcome. Liver Transpl Surg 1998;4(5 Suppl 1): S24-33.

4. Arnon R, Kerkar N, Davis MK, Anand R, Yin W, GonzálezPeralta RP, et al. Liver transplantation in children with metabolic diseases: the studies of pediatric liver transplantation experience. Pediatr Transplant 2010;14:796-805.

5. Kim ST, Park YH, Lee KU, Yoon YK, Kim SW, Yang HK, et al. An experience of liver transplantation in Korea. J Korean Soc Transplant 1988;2:27-36.

6. Busuttil RW, Klintmalm GB. General criteria for pediatric transplantation. In: Busuttil R, Klintmalm G, eds. Transplantation of the liver. 2nd ed. Philadelphia: Elsevier Saunders; 2005. p. 288-91.

7. Kim JM, Lee SK, Kwon CH, Joh JW, Choe YH, Park CK. Hepatocellular carcinoma in an infant with biliary atresia younger than 1 year. J Pediatr Surg 2012;47:819-21.

8. Kim JM, Kim KM, Yi NJ, Choe YH, Kim MS, Suh KS, et al. Pediatric liver transplantation outcomes in Korea. J
Korean Med Sci 2013;28:42-7.

9. Lee S, Kim JM, Choi GS, Kwon CH, Choe YH, Joh JW, et al. Sustained linear growth and preserved renal function in 10-year survivors of pediatric liver transplantation. Transpl Int 2015;28:835-40.

10. Lee S, Lee SK. Pediatric liver transplantation. J Korean Assoc Pediatr Surg 2013;19:14-21.

11. Choi Y, Lee KW, Hong G, Kim H, Park MS, Suh S, et al. Status and current problems in the allocation system for pediatric liver transplantation in Korea. J Korean Soc Transplant 2012;26:196-201.

12. Korean Network for Organ Sharing (KONOS). Status of organ donation [Internet]. Seoul: KONOS; 2014 [cited 2019 Mar 20]. Available from: https://www.konos.go.kr/konosis/ index.jsp.

13. United Network for Organ Sharing (UNOS). Organ distribution: allocation of livers [Internet]. Richmond, VA: UNOS; 2011 [cited 2019 Mar 20]. Available from: https:// optn.transplant.hrsa.gov.

14. United Network for Organ Sharing (UNOS). Ethical principles of pediatric organ allocation [Internet]. Richmond, VA: UNOS; 2011 [cited 2019 Mar 20]. Available from: https:// optn.transplant.hrsa.gov.

15. Korean Network for Organ Sharing (KONOS). Related legislature, guidelines, and regulations [Internet]. Seoul: KONOS; 2014 [cited 2019 Mar 20]. Available from: https://www. konos.go.kr/konosis/index.jsp. 